\title{
Comparing the Costs and Benefits of Attending the Top Three U.S. Elementary Teacher Education Programs
}

\author{
Mohammed Sabrin ${ }^{1}$ \\ ${ }^{1}$ College of Education, Taibah University, AlMadinah AlMunawwarah, Kingdom of Saudi Arabia \\ Correspondence: Mohammed Sabrin, College of Education, Taibah University, AlMadinah AlMunawwarah, \\ Kingdom of Saudi Arabia. Tel: 1-302-404-3850. E-mail: msabrin@taibahu.edu.sa
}

Received: March 4, 2018

Accepted: March 20, 2018 Online Published: April 9, 2018

doi:10.5539/hes.v8n2p70

URL: https://doi.org/10.5539/hes.v8n2p70

\begin{abstract}
This paper analyzed the costs and benefits of attending the top three U.S. elementary teacher education programs by examining how much emphasis is on general content knowledge (GCK), as opposed to general pedagogical knowledge (GPK), as opposed to methodological pedagogical knowledge (MPK), and how this ratio might have affected student outcomes on TIMSS compared to the top performing TIMSS countries in Europe and Asia. Three theoretical frames of reference guided this analysis: program model, field experience model, and status of teacher in society. Methodologically, this study relied mainly on peer-reviewed literature published between 2000 and 2016 in the English language. It was found that although the ratio of GCK to GPK to MPK in the top three U.S. TED programs was similar to what has been reported about the top performing TIMSS countries, student outcomes on TIMSS don't seem to have been affected due to the fact that performance on TIMSS seems to be stemming mainly from having a very rigorous K-12 education and only admitting the top academic achievers into TED programs.
\end{abstract}

Keywords: teacher education, TIMSS, U.S., comparative study

\section{Introduction}

This paper analyzes the costs and benefits of attending the top three U.S. elementary teacher education programs by examining how much emphasis is on general content knowledge (GCK), as opposed to general pedagogical knowledge (GPK), as opposed to methodological pedagogical knowledge (MPK), and how this ratio might have affected student outcomes on TIMSS compared to the top performing TIMSS countries in Europe and Asia. This study relied mainly on peer-reviewed literature published between 2000 and 2016 in the English language. We will now turn to three theoretical frames of reference that guided this study.

There is a spectrum of initial teacher education models found globally ranging from the concurrent to the consecutive. The consecutive model is where students receive a bachelor's degree in a particular subject and then enroll in a Diploma or Masters level program of TED at the end of their degree. The concurrent model is that which combines specialized education in one or more academic subjects with TED (coursework and field experiences) throughout the completion of the bachelor's degree and sometimes graduate studies. The OECD countries for example can be generally categorized as belonging to one of these two categories or having both options within the same country (Ingvarson, L., Schwille, J., Tatto, M.T., Rowley, G., Peck, R., \& Senk, S.L, 2013, pgs. 24, 50). 11 of 35 and 17 of 22 OECD countries with available data require a M.S. degree for primary level and secondary level teaching respectively (OECD, 2014, p. 502). These two TED models will be important indicators for describing the general framework of TED programs in this study,

The second theoretical reference point for this study will be the type of partnership followed between universities and the institutions where their field experiences take place. Some scholars (Buitink and Wouda 2001 in Maandag, D.W., Deinum, F.F., Hofman, W.H. Adrian, Buitink, J., 2007) have tried to synthesize the different types of collaboration between schools and universities into five models: school as workplace (work placement model); school with a central supervisor (coordinator model); trainer in the school as a trainer of professional teachers (partner model); trainer in the school as the leader of a training team in the school (network model); and training by the school (training school model). The main difference along this spectrum is that power and responsibility of the university gradually secedes to the school going from the first to the fifth model. This paradigm will be applied to TED field experiences in this study when enough data is available to classify. 
The third theoretical reference point for this study will be the status and role of teachers in the society as categorized by position-based or career-based. Generally, the former is more centralized and the teacher is a civil servant, compared to the latter being decentralized with more local decision-making and individual autonomy. Career-based countries are the likes of South Korea, Japan, and France-where all decisions regarding recruitment, pay, area of placement, and the like, are through the ministry of education; salaries in such systems tend to be much higher over time based on experience compared to position-based systems. Position-based countries are those like the U.S. and UK, where matters are usually decided at local, district, city, or statewide levels and salaries tend to flatten out much faster in such systems; however, the individual has more control over their career as a teacher. Career-based systems put the burden of finance, but luxury of control, with the government (particularly helpful when trying to avoid teacher shortages. Teachers in such systems have the luxury of semi-permanent jobs, but reduced freedom (Ingvarson, 2013, p. 112).

In sum, we could say that career-based positions are more prominent in more politically and culturally centralized countries; whereas position-based positions are in more politically and culturally individualistic (decentralized) or 'market-based' countries.

\section{U.S. TED}

\subsection{Context}

The U.S. did not make the top 10 in the TIMSS Math rankings for 2011 (the most recent TIMSS data published) in $4^{\text {th }}$ grade, but did rank number 9 in Math for the $8^{\text {th }}$ grade level. As for Science, U.S. students achieved holistically better--ranking $7^{\text {th }}$ in $4^{\text {th }}$ grade and $10^{\text {th }}$ in $8^{\text {th }}$ grade (TIMSS, 2016). The U.S. has both consecutive and concurrent forms of TED and could probably be said to have all the partnership options discussed above between university and school due to the country's sheer size and decentralized motley of TED programs. U.S. TED is position-based.

TED in the U.S. has become relatively much more centralized in recent years (compared to its status prior to the 1990s for example) with the advent of the national Common Core standards; however, since these standards are so general they are interpreted and applied in a myriad of ways across the United States, particularly from state to state. In 2003, the roughly 1,200 schools and departments of education in the U.S. produced 106, 000 teachers in undergraduate programs (61\% of total graduates), and 63,000 teachers in Master's programs (36\%), and about 4,000 teachers from certificate programs (3\%).

There is a disparity however between these numbers and those that actually enter the teaching profession in the U.S., due to the teacher shortage in poor urban areas. For example, in 2008 about $25 \%$ of newly hired teachers entered schools with no certification through methods such as waivers or emergency permits. As of $2008,20 \%$ of first year public and private schoolteachers entered with a Master's degree or higher. Above $10 \%$ of public school teachers are uncertified, and about $15 \%$ enter teaching through shortened alternative certification methods such as 'Teach for America'; these teachers tend to teach in poor urban areas due to teacher shortage in such areas (Darling-Hammond, 2012, p. 135). Such a situation is due to the well-known disparities between funding of affluent districts compared to marginalized ones, the former sometimes reaching triple the latter within the same state. Hence, salaries, class sizes, availability of resources, technology, and specialists, as well as facilities also reflect this monetary disparity. Just as important is that there is a proverbial glass ceiling on how competitive state legislatures will allow TED programs to be when they have a vested interest in keeping standards relatively low so that more teacher candidates are produced (which brings significant revenue particularly to universities and sometimes their surrounding communities) and salaries are kept low.

What can be generalized is that the majority of TED that takes place in the U.S. is done at public colleges or universities during a concurrent undergraduate degree that ends with certification to teach within that particular state. Such programs typically include coursework that consists of: general university requirements (usually consuming the first two years of the four); general pedagogical courses; methodological pedagogy courses; fieldwork; a portfolio proving skills acquired; and a concluding certification exam (ACE, 2004; Sullivan, 2015). The infamous teaching portfolio in particular is a hallmark of most U.S. TED programs and consists of a performance based approach to assessing student readiness for teaching (as opposed to relying just on the paper/pen exam which have not been reliable indicators of future performance) where students make an argument for their preparedness for teaching through: videos of teaching, work samples (such as lesson plans), and written analysis and reflection on the aforementioned (Darling-Hammond, 2012, pgs. 143-146). Given that the most significant disparities in achievement between U.S. TED programs are those between the typical TED programs in the U.S. just described, and those practiced at more elite ivy league style institutions (such as those ranked as the top in the country), particular attention will be paid to the top three in the latter category. 
Yearly rankings such as those of U.S. News and World Report are not without their controversies (Strauss, 2013); however, since they are widely presumed as reliable indicators of quality education at the moment, this research will take a look at the programs of Harvard, Stanford, and John Hopkins Universities.

\subsection{Harvard University TED}

Harvard University's undergraduate teacher education program (UTEP, 2016) allows students to complete teacher certification through a mere six courses taken in two back-to-back semesters. UTEP is a concurrent program. Coursework is completed in conjunction with fieldwork in a curriculum that requires 100 hours of fieldwork (observation) in the first semester called a pre-practicum (the equivalent of two full work days per week). Students complete UTEP requirements during their junior or senior year, or split between these years. During the second semester, students complete a practicum of 360 hours of teaching. The regular coursework between these two semesters at the university consists of: one specialization course (English, Math, History, and Science) for teaching methods, one course in educational foundations, one course in psychology, and one course in teaching ELLs.

As noted above, a key highlight of the Harvard UTEP program is that students complete fieldwork at the same time as their coursework; this is a key component of successful TED in many of the top performing OECD countries (Darling-Hammond, 2012). The pre-practicum mentioned above focuses on: observing a seasoned mentor teacher; assisting students one-on-one, and in small groups; delivering short chunks of instruction; and participating in relevant meetings and workshops at the school site. The practicum is full-fledged teaching. Since U.S. teachers are position-based, and not civil servants, it is difficult to require a graduate degree for teachers through the federal government; however, through a market-based economy competition has pressured elite universities to offer graduate options.

Harvard also offers a graduate level teacher education program (TEP, 2016) similar to the undergraduate one, but expectedly more rigorous and offering more diverse options in theoretical courses in the curriculum. Of course, there is also a better student-teacher ratio, being a graduate program. There are two teacher licensure paths in the program: teaching and curriculum (TAC), which is designed for recent college graduates and experienced professionals (in the humanities, math, and science) who plan to teach in urban public middle and high schools; and the Mid-Career Math and Science (MCMS) track, which is designed exclusively for mid-career professionals in math and science related fields who plan to teach math and/or science in urban public middle and high schools. The TEP curriculum spans 11 months, 36 credits, and 675 hours of classroom teaching. The coursework is essentially the same as the undergraduate version of the program, with the addition of more theoretical courses as options among the extra required electives like: "Inquiries into Adolescence: Understanding and supporting the Development of Urban Youth"; "Dimensions of Diversity: English Language Learners"; "Race and Power in Urban Classrooms"; "A Practical Approach to Classroom Management"; and "Elements of Diversity: Special Education." It is well known that the biggest difficulties in teaching at the moment in the U.S. are primarily in the poor marginalized urban areas of American cities; hence, there is a clear emphasis on such topics throughout much of the theoretical coursework that takes place in the U.S. Offering a plethora of electives such as this is also a cornerstone of successful TED programs as has been seen in European and Asian TED studies (Sabrin, 2018a, 2018b).

The recent trend of holding TED at the graduate level is one that is being practiced increasingly more in recent years, not unimportantly in countries that top the TIMSS and PISA rankings like Finland. This is often part of the 'professionalization' of the teaching profession that has been occurring over the last few decades, and the new view of the teacher as a reflective researcher with increased autonomy (Darling-Hammond 2006 as cited in Darling-Hammond 2012).

Upon completion of the TEP, students receive an initial teaching license for Massachusetts (where Harvard is located), which is valid for five years; however, students must also pass the Massachusetts Tests for Education licensure (MTEL) in their content area and in Communication and Literacy Skills. This is important since in the U.S. most states require their own specific licensure certificates, which are not usually valid in other states. This point is something that could be changing with the current push for national certification in recent years (Darling-Hammond, 2012.).

It has probably been noticed that the Harvard graduate program focuses on middle and secondary education; nonetheless, any TED programs that include 'middle -school' preparation will also be included in this study since much of what is termed 'primary level' teacher certification and TED in the U.S. includes grades five through eight. In international studies that will be discussed, middle-school is also sometimes referred to as 'lower-secondary', even though it is not technically part of high-school in such countries; given the overlap and 
the absorption of middle-school into the term 'primary' in some countries, it has been included in this study where relevant. Harvard's inclination toward the concurrent model for both their undergraduate primary certification, and their graduate middle/secondary certification, seems to highlight a strong belief that although middle/secondary preparation might require more advanced study, it shouldn't have to sacrifice a concurrent experience where subject matter is taught simultaneous to it's appropriate methods and pedagogies. Such a view has also been found among successful TED programs in Europe and Asia.

\subsection{Stanford University TED}

As for Stanford University, it doesn't offer an undergraduate TED program, just a graduate level one. This seems to be an implicit stance on the belief in the necessity of graduate education for at least future elementary teachers. Stanford's elementary level TED (STEP, 2016), is a 12-month program leading to a Master of Arts in Education and a preliminary California Multiple Subject Teaching Credential at the primary level.

Once again, due to its graduate status, program size is approximately a mere 20 students, an appealing selling point for applicants given the established link between one-on-one supervisory relationships and teacher quality. Although about the same amount of months, the coursework at Stanford is particularly more structured than what is reflected on paper at Harvard University; this is reminiscent of the top performing Asian countries (Sabrin, 2018a), in contrast to the top European ones (Sabrin, 2018b). Stanford's programs are also much more inter-disciplinary in its coursework, compared to Harvard which reflects the traditional 'back to basics' theme that is more common as one progresses up the aristocratic ladder in academia. The latter theme is a well-known characteristic of the ivy league view that education generally does little to change individual intellectuality, ability, maturity, etc. In this sense, Stanford is once again more similar to the top performing European countries (Sabrin, 2018b), in contrast to the Asian ones (Sabrin, 2018a).

There is a very explicit, targeted, and more rigorous study plan at Stanford as can be gleamed from the course titles (Appendix A), which has virtually no choice in what courses are taken; undoubtedly, it seems to be a much more challenging study plan in that it forces students to specialize essentially in everything. This is possibly going a step beyond what occurs in some European (Sabrin, 2018b) and Asian countries (Sabrin, 2018a) whereby students are required to often have a double major or minor. Students are even required to undertake their fieldwork at three different professional development schools (PDSs) for a versatile experience that reflects the diverse situations ahead of them, teaching in the areas where most positions are available in the U.S. at the moment-urban public schools. Fieldwork experiences in diverse contexts are a key trait of successful TED globally (Darling-Hammond, 2012)). These are much stronger selling points as well given that graduates will be much more marketable to future employers since they can apply to essentially any primary level teaching position and be qualified to teach any subject in almost any U.S. context. The rigidity in the STEP program also shows a clear confidence among the faculty (which is reflected in their research) in identifying what they believe to be clear indicators of quality TED.

Also, in STEP particular attention is paid to matching teacher candidates with "cooperating teachers" that share STEP's vision of education; this is reflective of Stanford's acknowledgment of the commonplace tensions that arise between university liaisons and school mentors where the student-teacher is often caught in the middle between conflicting ideas of good education and is appraised according to two different sets of standards. This university-school relationship might be considered a work placement model. While many universities use the term 'mentor teacher', even Stanford's explicit use of the term "cooperating teachers" is a clear indicator that they intend to be leading the student's TED program, including the fieldwork portion. A common vision between university and professional development school is a key characteristic of productive field experiences globally (Darling-Hammond, 2012). STEP requires a total of 45 credits for graduation and certification.

\subsection{John Hopkins TED}

As for John Hopkins University, it also only offers TED at the graduate level (Master's Programs, 2016). Again, this should not be mistaken for a consecutive program merely because it is at the Masters level since one could enroll after a Bachelors in a subject matter (in which case it would become a consecutive experience for that particular student), or after a bachelors in education in general (in which case it would be a concurrent bachelors followed by a concurrent Masters). Its Master of Arts in Teaching (MAT) is a 39 credit program that offers certification and is accepted reciprocally in most U.S. states. Similar to Stanford, John Hopkins' TED program stands out in its rigor as well as the diversity of specializations that are all required to complete the program and attain certification. There is very little choice in the program (see Appendix B), which forces student teachers to take courses and be tested for competence on essentially every aspect of teaching-including all the main subject areas. John Hopkins, like Stanford, does not allow student teachers to focus in one content area as Harvard's 
TED program does. As mentioned above, this is an extremely strong selling point of such programs since they challenge students to have to be competent in any possible circumstance that could arise within the school environment, including having to help other teachers who teach other subjects through the various collaborative initiatives that consistently take place in schools.

The Master of Arts in Teaching is designed for recent graduates of bachelor's or graduate degree programs, as well as working professionals who want to become teachers. The MAT program offers three options: a full-time Master of Arts in Teaching; the Montgomery County Public Schools full-time Partnership, and the Part-time Master of Arts in Teaching. We will discuss these one by one.

The full-time Master of Arts in Teaching at JHU offers three tracks. The Baltimore Education Fellows program is available to JHU Arts and Sciences graduates only, and is supported by a scholarship and living stipend. The Traditional Master of Arts in Teaching (MAT) option is available to candidates who do internships in both urban and suburban settings. Applicants accepted to the full-time MAT program for the 2016-2017 cohort for example will be awarded a $\$ 10,000$ scholarship from the School of Education. The total tuition cost of the full-time program after the award of the scholarship will be $\$ 29,000$. The Montgomery County Partnership Master of Arts in Teaching (MCPROMAT) is open to Secondary STEM candidates and is partially supported by Montgomery County Public Schools through tuition assistance. Although none of these programs hold a candle to the type of financial compensation awarded to TED students in countries like Finland, they are uniquely generous in the U.S context. The first program is paid in full--like the top European and Asian TED programs--(Sabrin, 2018a, 2018b); the second and third MAT tracks are partially funded. However, the university and not the state, unlike their European and Asian counterparts, fund all three programs.

All three of these programs offer a very disciplined approach to TED given that they require students to participate in experiences (coursework and fieldwork) over 12-18 months non-stop, even in the summer (which is very rare in the U.S.). Structuring a program in this fashion is no doubt part of the screening process in only accepting applicants who are extremely highly qualified academically, passionate, and have the disposition needed for successful teachers. Having an outstanding academic record is one of the indicators globally to have been found to contribute profoundly to the future performance of students in TED programs, or thereafter as teachers as will be discussed. Passion and disposition are also global indicators of teacher quality (Darling-Hammond, 2012). The Elementary track of these programs is defined as first through sixth grades, plus middle school (seventh and eighth). Also pivotal is that these three JHU programs require multiple fieldwork placements at different sites to provide diverse experiences that try to imitate what beginning teachers will find in their future positions, just like Stanford, but unlike Harvard. Also similar to Stanford is that JHU takes an explicit lead role in the University-school partnership. We could also categorize its university-school relationship as work placement similar to Stanford. JHU faculty members do not only provide supervision of student teachers, but also conduct professional development activities for mentor teachers.

One unique difference that is noted with JHU however, is that it has explicit content knowledge admission requirements that must be added on to the graduate program requirements if they have not been met during their regular undergraduate coursework. This is most likely not haphazard given the global push for more subject content focus in TED programs over the last 20 years. Also, it seems as we progress lower in the rankings of U.S. TED programs, standards are ironically raised to make up for what are perceived to be weaker students entering; this point will be returned to in the conclusion.

Aside from the traditional program above, there are also other options at JHU's TED program. There is a part-time Master of Arts in Teaching (MAT) option which essentially has the same academic requirements as the traditional track, but it allows students to progress in the course work at their own pace within the 5-year time limit set for completion of the degree. Candidates take courses with full-time MAT candidates and are eligible for certification. One poignant difference from the full-time version of this program is that as the final step in the program, candidates complete a full-time, 100-day clinical internship over two semesters during which time they are not allowed to hold outside employment, unless they are a full-time teacher in their own private or public school classroom. This is most likely to cultivate their new identity as a teacher and is a practice similar to what is seen in the top performing Asian countries (Sabrin, 2018a).

Secondly, there is a partnership between JHU SOE and Montgomery County Public Schools (MCPS), which offers a Master of Arts in Teaching degree for those interested in becoming certified teachers. The partnership provides some tuition support and a full-time internship as a long-term substitute in MCPS schools. The program begins each spring and is completed in approximately 16 months. Applicants must commit to teach in Montgomery County Schools for two years after completion of the University requirements. Such a requirement 
has also been found in the top performing European and Asian TIMSS countries (Sabrin, 2018a; 2018b).

The emphasis on financial assistance in JHU's TED programs should be reiterated since students are often expected to not work as has been noted, unless in related teaching positions, while in the program. Also, normally Masters level education in the U.S. is known to be the most difficult in getting financial assistance for, since one is no longer eligible for typical federal funding like PELL grants, and is second in consideration (after doctoral students) for graduate department funding.

There are other TED programs that don't directly offer certification within them at JHU and serve more as continued adult education for existing teachers; however, since they don't fit the traditional definition of pre-service TED, which is the focus of this paper, they won't be elaborated on here.

\section{Analysis and Discussion}

At this point it is worth mentioning two important points regarding the inclination one might feel towards logically trying to imitate the aforementioned structures of the top three ranking colleges of education in the U.S. The first is that a recurring point that is found throughout U.S. TED programs is that although they: offer courses that, generally speaking, sound the same and are housed within TED programs that are relatively similar; due to the tremendous academic freedom even at the departmental level of U.S. universities, what is actually taught widely varies even from department to department within the same College of Education, depending mostly on individual faculty members' research interests, funding (like grants and fellowships), and other factors (ACE, 2014).

The second point is that there is a persuasive body of international research that points to the fact that although students that attend such institutions of TED in the U.S. have had the best academic opportunities generally leading all the way up to their undergraduate/graduate TED program, there doesn't seem to be any evidence that the TED program itself at such private/ivy league institutions has provided any idiosyncratic addition to their academic skills, particularly in the academic subjects of interest here like Math (Schmidt, Burroughs, Cogan, and Houang, 2014). Essentially, there is the problem of selection bias: students graduating from elite higher education institutions tend to have more prestigious careers due to their degrees; however, their alma maters have such clout due to largely endowment-based reputations, high tuition prices, peer effects, and superb networking opportunities. "There is every possibility that students at the most selective postsecondary institutions would do just as well having gone somewhere else" (Schmidt, et al, 2014, p. 504).

While the aforementioned might seem like a strong position to take, it is based on a quite convincing set of recent data from a U.S. teacher education study in mathematics which provided data on the educational experiences and content knowledge gains of a nationally representative sample of future teachers prepared at a wide variety of instructions (private and public). The International Association of the Evaluation of Educational Achievement (IEA), the same organization that conducts the TIMSS study, sponsored the study. The sample was of 900 future 'lower-secondary' teachers ${ }^{1}$ in their final year of TED preparation at 81 U.S. postsecondary institutions and compared their mathematical content knowledge before and after their TED programs as measured primarily by their previous mathematical coursework and SAT scores (before), and Future Teacher Mathematical Content Knowledge test (after). The study found that students at elite institutions in the U.S. did not perform statistically better than their TED counterparts at normal public U.S. institutions, and sometimes even performed comparatively less after their TED program. There was also found to be just as many high performing students at average public institutions as there were at elite institutions, reaffirming that there seems to be little advantage to attending an elite institution from a purely cost-benefit perspective of tangible factors. The future salary of a teacher will be relatively dismal compared to the investment of tuition and other expenses at an elite U.S. institution.

While this study and others using the same data set (Cougan, Schmidt, Houang, 2014), has shown that a rigorous math curriculum (measured by the increase of the amount of raw hours of mathematics courses, as well as those in advanced mathematics courses) has a statistically significant relationship with the proficiency of TED graduates in mathematics at U.S. institutions, there is no statistical relationship with attending elite institutions as

\footnotetext{
${ }^{1}$ This term coined by UNESCO is part of the International Standard Classification of Education (ISCED) levels, which is used to compile internationally comparable statistics on education. It refers to grades 7-9 when applied to the U.S., although grades 7-8 are generally part of 'middle school' in the U.S. and usually fall under the certification received for 'primary/elementary' teachers in the U.S. Hence, the UNESCO term 'lower-secondary' is applicable to $2 / 3$ of the 'primary/elementary' focus of this study (NCES). https://nces.ed.gov/pubs/eiip/eiip1s01.asp. Secondary, as in high-school, education as a whole doesn't generally start until $9^{\text {th }}$ grade in the U.S.
} 
those discussed above for example. The above research also highlighted that "students who know relatively more entering teacher preparation programs gain relatively more knowledge by the time they graduate" (p. 511). Students having advanced knowledge in mathematical content prior to the TED program were typically those having taken advanced high school mathematics courses and having achieved high SAT scores; these students were also the ones most likely to have achieved higher mathematical content knowledge scores on the 'post test' discussed above.

Furthermore, there also seems little relative benefit to attending elite U.S. institutions compared to public ones because the U.S. does not perform well in regards to its regular k-12 student population as well as its mainstream undergraduate TED population when compared internationally. This seems to reaffirm the fact that if one is going to imitate the TED practices of U.S. (or any other nation's TED) universities, one should compare with universities that accommodate students from similar socioeconomic situations and yet have superior academic outcomes. Such an approach seems to be wise policy in acquiring appropriate solutions for improving the quality of TED.

\subsection{Further Directions for Research}

Probably one of the most important data sets in TED in the last five years has been the TEDS-M data set which researched nationally representative samples of primary and lower secondary mathematics future teachers in their final year of teacher training in 16 countries, as well as nationally representative samples of teacher educators and their institutions). More than 13,000 future math teachers participated. Generally speaking the data set confirmed the overwhelming consensus of the TED professional community, that: teacher education is one of the most important factors affecting teacher quality, and teacher quality is one of the most important factors (within the realm of the field of education) that affects student achievement (Blomeke, et al, 2014). However, there have also been some other surprising findings from this data set.

In a study by Cogan, Schmidt, and Houang (2014), it was found that the performance of U.S. student teachers in math is about the international average. Also, U.S. division of time and coursework between GPK, GCK, and MCK, is also roughly the international average. This led the authors to hypothesize that the only variables that seemed to react positively and make the difference for why other countries who spent the same amount of time on math subject matter as the U.S., had higher achievement in math was that the pool that future teachers were chosen from was better (students entering their TED programs were more academically advanced in math than their U.S. counterparts), and the intensity of these Asian countries' math courses are known to be much higher.

These findings coincide with the results of another study by Schmidt, Cogan, and Hougan (2014) that found that the major difference between the U.S. and top performing countries in math is that they don't just offer more intensive math courses, but more of them. The top countries allocated roughly half their TED to math , and by a ratio of three to two more mathematics pedagogy courses than general pedagogical ones.

In yet another study by Schmidt and Cogan (2014), the exact math courses that the top achieving countries enforce were found to be: beginning calculus; calculus; linear algebra; probability; differential equations; multivariate calculus; mathematics instruction and observation; analysis and reflection of mathematics teaching; and functions, relations, and equations. Respectively, these are six university level math courses, two math education courses, and one school mathematics topic. Over $90 \%$ of the teachers in the 39 TED programs in this study (spread over 3 continents) took these courses. The U.S. had six programs in the top 39, and the requirements at the top 10 math performing TED institutions in the U.S. had coursework that was all required in the international set of 9 courses above. However, generally speaking the U.S. stressed math education more than math; unlike the top performing countries where the pattern is reversed. Aside from the issue of intensity mentioned above, it seemed that the vast majority of math courses taken at U.S. TED programs were in fact school, and not university level math courses. We might hypothesize that this is probably another indicator of the often low mathematical ability of teacher candidates entering TED programs in the U.S.

The last study to be discussed is by Konig, et al (2014) which explored what good quality GPK looks like in a study comparing Taiwan, Germany, and the U.S. In the U.S. for example, such a category might be covered by 'foundations of education' and 'teaching methods'; whereas in other countries such a category might be covered by courses such as educational psychology and sociology of education. Focusing on general instructional methods, it was found that the U.S. was outperformed by both countries (one and a half standard deviations in the case of Germany for example) in declarative knowledge, but was stronger in procedural knowledge. Hence, depending on what a country needed, it could adapt accordingly from the TED programs of these countries on these topics.

In conclusion, there was no evidence found that the three frames of reference that guided this study-model of 
TED (concurrent or consecutive), nature of collaboration for field experiences, and the role of teacher in society were as important as the ratio of GCK to GPK to MPK in a TED program. Furthermore, although the ratio of GCK to GPK to MPK in the top three U.S. TED programs was similar to what has been reported about the top performing TIMSS countries, student outcomes on TIMSS don't seem to have been affected due to the fact that performance on TIMSS seems to be stemming mainly from having a very rigorous K-12 education and only admitting the top academic achievers into TED programs.

\section{Acknowledgements}

I'd like to thank Dr. Niaf Al-Jabri and Badr Alshaairy for their time and efforts in helping me reflect on the nuances of this paper.

\section{References}

American Council on Education (ACE) (2014). Teacher education programs in the United States: A guide. Washington D.C.: Praeger Publishers.

Blomeke, S., Hsieh, F., Kaiser, G., \& Schmidt, W. H. (eds) (2014). International Perspectives on teacher knowledge, beliefs and opportunities to learn. Springer. https://doi.org/10.1007/978-94-007-6437-8

Blomeke, S. (2014). Framing the enterprise: Benefits and challenges of international studies on teacher knowledge and teacher beliefs-modeling missing links. In Blomeke et al (eds). International Perspectives on Teacher Knowledge, Beliefs, and Opportunities to Learn, Advances in Mathematics Education. Springer. https://doi.org/10.1007/978-94-007-6437-8_1

Blomeke, S., \& Kaiser G. (2014). Theoretical framework, study design and main results of TEDS-M. In Blomeke et al (eds). International Perspectives on Teacher Knowledge, Beliefs, and Opportunities to Learn, Advances in Mathematics Education. Springer. https://doi.org/10.1007/978-94-007-6437-8_2

Cogan, L., Schmidt, W. H., \& Houang, R. (2014). Primary teacher preparation in the United States: What we have learned. In Blomeke et al (eds). International Perspectives on Teacher Knowledge, Beliefs, and Opportunities to Learn, Advances in Mathematics Education. Springer. https://doi.org/10.1007/978-94-007-6437-8_16

Darling-Hammond, L. (2012). Teacher preparation and development in the United States: A changing policy landscape. In Darling-Hammond, L. Editor \& Lieberman, A. Editor (Eds.), Teacher education around the world: Changing policies and practices. (Pgs. 130-150). New York: Routledge.

Darling-Hammond, L. \& Lieberman, A. (2012). Teacher education around the world: What can we learn from international practice. In Darling-Hammond, L. Editor \& Lieberman, A. Editor (Eds.), Teacher education around the world: Changing policies and practices. (Pgs. 151-169). New York: Routledge.

Darling-Hammond, L., Holtzman, D. J., Gatlin, S. J., \& Heilig, J. V. (2005). Does teacher preparation matter? Evidence about teacher certification, teach for America, and teacher effectiveness. Education Policy Analysis Archives, 13(42). https://doi.org/10.14507/epaa.v13n42.2005

Ingersoll, R., Gang, D., Meilu, S., Lai, K. C., Kim, E., Tan, S. K. S., Wong, A. F. L., Siribanpitak, P., Boonyananta, S. A Comparative Study of Teacher Preparation and Qualifications in Six Nations. Retrieved from: http://www.cpre.org/images/stories/cpre_pdfs/sixnations_final.pdf

Ingvarson, L., Schwille, J., Tatto, M. T., Rowley, G., Peck, R., \& Senk, S. L. (2013). An analysis of teacher education context, structure, and quality-assurance arrangements in TEDS-M countries: Findings from the IEA teacher education and development study in mathematics (TEDS-M). Retrieved from: http://www.iea.nl/fileadmin/user_upload/Publications/Electronic_versions/TEDS-M_Findings.pdf

Konig, J., \& Blomeke, S. (2014). Does school experience mater for future teachers' general pedagogical knowledge? In Blomeke et al (eds). International Perspectives on Teacher Knowledge, Beliefs, and Opportunities to Learn, Advances in Mathematics Education. Springer. https://doi.org/10.1007/978-94-007-6437-8_19

Konig, J., Blomeke, S., Paine, L., Schimdt, W. H., \& Hsieh, F. J. (2014). Teacher education effectiveness: Quality and equity of future primary and future lower secondary teachers' general pedagogical knowledge. In Blomeke et al (eds). International Perspectives on Teacher Knowledge, Beliefs, and Opportunities to Learn, Advances in Mathematics Education. Springer. https://doi.org/10.1007/978-94-007-6437-8_9

Maandag, D. W., Deinum, F. F., Hofman, W. H. Adrian, \& Buitink, J. (2007). Teacher education in schools: an international comparison. European Journal of Teacher Education, 30(2), 151-173. 
https://doi.org/10.1080/02619760701275552

Master's Programs (2016). Retrieved from: http://education.jhu.edu/Academics/masters/

OECD (2014). "Indicator D6: What does it take to become a teacher?, in Education at a Glance 2014: OECD Indicators, OECD Publishing. Retrieved from: https://www.oecd.org/edu/school/2713221.pdf

Sabrin, M. (2018) (forthcoming). A comparative policy analysis of elementary teacher education in the top performing Asian TIMSS countries. EDUCARE: International Journal for Educational Studies. (August).

Sabrin, M. (2018) (In Press). Elementary Teacher Education in the Top Performing European TIMSS countries: A Comparative Study. International Education Studies, 11(4).

Schmidt, W., Burroughs, N., Cogan, L., \& Houang, R. (2014). Are college rankings an indicator of quality education? Comparing Barron's and TEDS-M. In Blomeke et al (eds). International Perspectives on Teacher Knowledge, Beliefs, and Opportunities to Learn, Advances in Mathematics Education. Springer. https://doi.org/10.1007/978-94-007-6437-8_23

Schmidt, W., \& Cogan, L. (2014). Greater expectations in lower secondary mathematics teacher preparation: An examination of future teachers' opportunity to learn profiles. In Blomeke et al (eds). International Perspectives on Teacher Knowledge, Beliefs, and Opportunities to Learn, Advances in Mathematics Education. Springer. https://doi.org/10.1007/978-94-007-6437-8_18

Schmidt, W. H., Cogan, L., \& Houang, R. (2014). Emphasis and balance among the components of teacher preparation: The case of lower secondary mathematics teacher education. In Blomeke et al (eds). International Perspectives on Teacher Knowledge, Beliefs, and Opportunities to Learn, Advances in Mathematics Education. Springer. https://doi.org/10.1007/978-94-007-6437-8_17

Strauss, V. (2013). Why U.S. news college rankings shouldn't matter to anyone. The Washington Post. September 10, 2013.

STEP (2016). Retrieved from: https://ed.stanford.edu/step

Sullivan, S. (2015). Teacher Education in the United States. International Journal of Arts \& Sciences, 08(07), 497-507.

TIMSS (2016). Retrieved from: http://timssandpirls.bc.edu/

UTEP (2016). Retrieved from: http://static.fas.harvard.edu/registrar/ugrad_handbook/current/chapter2/UTEP.html 
Appendix A: Stanford Study Plan

STEP recognizes the integration of the many areas of knowledge that underlie effective teaching.

\section{Summer}

EDUC228E: Becoming Literate in School I ( 2 units) 2015 syllabus

EDUC244E: Elementary Classroom Leadership and Management ( 1 unit) 2015 sylabus

EDUC246E: Elementary Teaching Seminar (3 units) 2015 syllabus

EDUC263E: Quantitative Reasoning and Mathematics I ( 2 units) 2015 syllabus

Pre-fall/Fall

EDUC219E: The Creative Arts in Elementary Classrooms (1 unit) 2015 syllabur

EDUC228F: Becoming Literate in School II ( 2 units) 2015 syllabus

EDUC244F: Elementary Classroom Leadership and Managemen

EDUC246F: Elementary Teaching Seminar (5-7 units) 2015 sylabus

EDUC263F: Quantitative Reasoning and Mathematics II (2-3 unic

EDUC267E: Development of Scientific Reasoning and Knowledg:

EDUC299: Equity and Schooling (2 units) 2015 syllabus

EDUC283: Child Development in and Beyond Schools (2 units) 2015 milabus

EDUC388F: Introduction to Academic Language (1 unit) English ony 2 ns sylatus

EDUC264E: Metodos y Materiales en los Salones Bilingues ( 2 units) Blingua orty an's

syllabus

Winter

EDUC246G: Elementary Teaching Seminar (2 units) 2016 syllabus

EDUC263G: Quantitative Reasoning and Mathematics III ( 2 units) 2016 syllabus

EDUC267F: Development of Scientific Reasoning and Knowledge II ( 2 units) 2016 syllabus

EDUC269X: Ethics in Teaching (1 unit) 2014-2015 syllabus

EDUC388A: Language Policies and Practices (2 units) 2016 syllabus

Spring

EDUC228G: Becoming Literate in School III (3 units) 2016 syllabus

EDUC228H: Literacy, History and Social Science (1 unit) 2016 syllabus

EDUC246H: Elementary Teaching Seminar ( 5 units) 2016 syllabus

EDUC267G: Integrating the Garden Into the Elementary Curriculum (1 unit) 2015-2016 syllabus

EDUC285: Supporting Students with Special Needs ( 2 units) 2016 syllabus

"A minimum of 45 units is required for the master's degree and teaching credential, but teacher candidates may take up to 48 units without an additional charge.

CLINICAL WORK

Clinical Work

Work at STEP rests on the fundamental belief that the goal of educational enterprise is the success of all students, and that this goal should organize the connected work of both researchers and practitioners. It is possible for teacher preparation programs to see the point where universities and school sites connect as a space where theory and practice face off.

STEP strives to view this place as one where theory and practice meet and where, in turn, learning takes place. The links between theory and practice, university and school, experience and standards, are the links of learning. These links of learning are forged in part at the level of candidate placement. Pairing candidates with cooperating teachers who reflect STEP's vision of teaching is a priority for the program. Instead of selecting cooperating teachers based on selfnomination or principal recommendations alone, cooperating teachers are selected with direct, first-hand knowledge of their classrooms and teaching practices. With solid input from the 
Appendix B: John Hopkins’ Study Plan

\section{MAT Coursework}

The course sequence for both elementary and secondary certification are available below.

Click on the course name for an expanded description.

\section{Elementary Education}

\section{Number of Credits Required: 39}

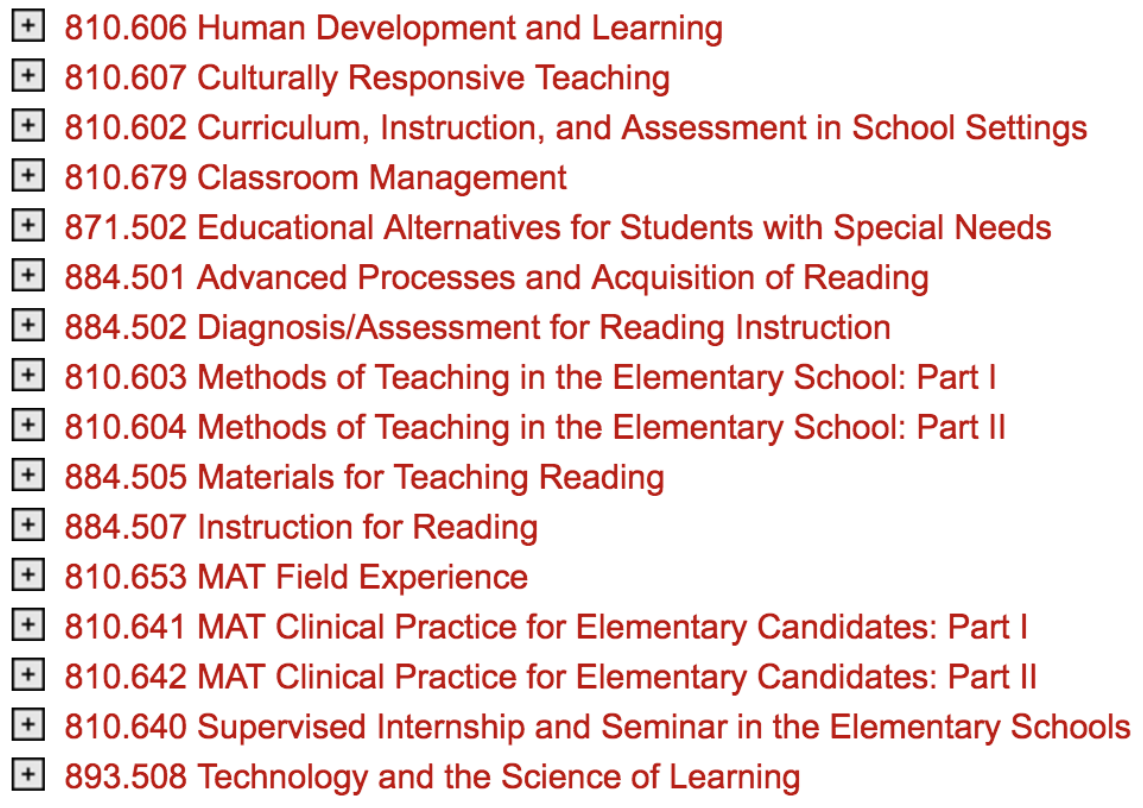

Funding Details: There are no funding details or potential conflicts of interest to disclose for this article.

Biographical Sketch:

Dr. Mohammed Sabrin completed his undergraduate education at The University of Delaware in English. He completed his Master's in Socio-cultural International Development Education Studies at Florida State University. He completed his $\mathrm{PhD}$ in Elementary Education at The University of Georgia. He is currently an Assistant Professor in the Foundations of Education department at Taibah University in Madinah, Saudi Arabia.

\section{Copyrights}

Copyright for this article is retained by the author(s), with first publication rights granted to the journal.

This is an open-access article distributed under the terms and conditions of the Creative Commons Attribution license (http://creativecommons.org/licenses/by/4.0/). 